\title{
DEVELOPMENT AND ASSESSMENT OF FREE-FLOW SPEED MODELS BASED ON DIFFERENT METHODS OF MEASUREMENTS FOR INTER URBAN MULTILANE HIGHWAYS IN MALAYSIA
}

\author{
Lee Vien Leong ${ }^{1 *}$, Tuti Azmalia Azaí ${ }^{2}$, Wins Cott Goh ${ }^{3}$, Shafida Azwina Mohd Shafie ${ }^{1}$ \\ ${ }^{1}$ Universiti Sains Malaysia, Malaysia \\ ${ }^{2}$ City Council of Penang Island, Malaysia \\ ${ }^{3}$ Intelliroad Services, Malaysia
}

This study aims to assess and compare several free-flow speed measurement methods that are suitable for Malaysian multilane highways. Free-flow speed is defined as a speed where the driver can maintain their own desired speed without obstruction or without being influenced by other road users. Data collection was conducted at 16 sites across Peninsular Malaysia during peak and off-peak periods. The measurement methods use different criteria which includes linear speed-density relationship graphs, the average speed of vehicles recorded during low to moderate traffic volume and also the average speed of vehicles with a pre-determined headway. Subsequent analysis was conducted and compared by performing multiple regression analyses. Results indicate that measurement of freeflow speed based on pre-determined headway is the best-suited model for Malaysian multilane highways. The model was determined as the best fit due to its highest $R$ value of 0.954 and the highest score of 12/15 for the performance indicator analysis. These findings can greatly contribute to traffic engineers of Malaysia in determining a more precise free-flow speed for the design and operational assessment of multilane highways in Malaysia.

Key words: Free-flow speed, Headway, Measurements methods, Multilane highways, Speed-density, Traffic volume

\section{INTRODUCTION}

Based on the definition given in the Highway Capacity Manual 2010 (HCM 2010) [1], multilane highway is a highway with at least two lanes or more for the exclusive use of traffic in each direction, with no control or partial control of access, which may have periodic interruptions to flow due to the presence ofsignalised intersections with a distance of more than $3.0 \mathrm{~km}$. Free-flow speed can be defined as the speed of a vehicle at which the drivers feel comfortable to travel under prevailing geometric, environmental and traffic control conditions; and not be restrained by any other vehicles. Alternatively, free-flow speed can also be defined as the hypothetical average speed of vehicles when traffic volumeson the actual roadway conditions are very low $[1,2]$.

In relation, free-flow speed can be measured either empirical or estimated using theoretical approach. For theoretical approach, free-flow speed can be estimated based on regression models or speed-flow-density models. Generally, speed-density relationship shows that when the density and flow of the vehicle approaches to zero, the speed of the vehicle will approach free-flow speed condition. Speed-density models developed by Greenshield, Greenberg and Underwood are the more popular methods used to estimate free-flow speed. These models assumed that free-flow speed occurs when the driver could drive at any desirable speed at low density on a single roadway. When more and more drivers begin using the roadway, density increases, and the speed decreased significantly till the road capacity is reached [3]. At a point in time, density becomes so high such that all vehicles stop, and speed is zero. Initially, Greenshield developed free-flow speed model for uninterrupted traffic flow in year 1935. This model assumed that speed and density relationship is a linear model. However, the other model developed by Greenberg suggested that the logarithmic curve is a more suitable curve to express the relationship between speed and density. However, a main problem of this model is that this model is unable to predict speed at lower densities as at low density, speed tends to be infinity [4]. Therefore, in order to overcome this limitation, Underwood developed and exponential model but, in this model, speed only becomes zero when density reaches infinity, hence it is unable to predict speed at high densities.

Apart from theoretical models, there are other methods which can be used to measure free-flow speed from the field. The typical criterion used to measure speed of vehicles under free-flow condition is based on certain pre-determined threshold value of vehicle headway travelling in the traffic stream.Studies conducted by Figueroa and Tarko [5], Gong and Stamatiadis [6], Himes and Donnell [7], Tseng et al. [8], Saifizul et al. [9] and Sekhar et al. [10] on free-flow speeds adopted headway threshold value of 5 seconds to measure free-flow speeds while studies conducted by Bang et al. [11], Chiguma [12], Ghani et al. [13], Al-Kaisy\&Karjala [14] and Ministry of Works Malaysia [2] adopted higher headway threshold value in which they only considered the speed of vehicles travelling with headway equal to or greater than 8 seconds as free-flow speeds. However, based on a study conducted by Ali et al. [15] to investigate the relationship between free-flow 
speed and geometric variables of urban roads in Fairfax County in Virgina, they considered speeds of vehicles travelling with lead headways of at least 7 seconds and lag headway of at least 4 seconds as free-flow speed. In another study conducted by Silvano and Bang [16] to investigate the effect of posted free-flow speed on freeflow speeds on urban roads in Sweden, they use headway threshold value of 10 seconds to measure free-flow speed. However, in a study conducted by Wu et al. [17] to investigate the difference between free driving and car following based on trajectory data, they observed a longer time gap threshold value of 12 seconds between free driving and car following.

Aside from using the headway criterion, there are studies which determine free-flow speed based on the average speed of vehicles measured on actual road conditions during low traffic flow. Dixon et al. [18] and HCM 2010 [1] suggested that the average operating speed during low volume conditions is similar to free-flow speed. Based on the method adopted in the HCM 2010 [1], the measurement of mean free-flow speed of vehicles must be observed during low to moderate traffic volume, in which the flow of vehicles must be less than $1400 \mathrm{pc} / \mathrm{h} / \mathrm{ln}$ and speeds of at least 100 passenger cars must be obtained. However, Deardoff et al. [19] suggested that vehicles with headway more than 7 seconds is considered as a free-flow condition and observation of speed must be conducted at low traffic volume of less than $500 \mathrm{veh} / \mathrm{h} /$ In. In the study conducted by Andrade et al. [20] to develop the free-flow speed estimation model for Brazilian Expressways, they determined free-flow speed based on the speed-flow data collected in short time intervals using inductive loops. Only the average speed of vehicles for intervals with flow rates equal to or less than 350 $\mathrm{pc} / \mathrm{h} / \mathrm{ln}$ and heavy vehicles and motorcycles of less than $5 \%$ were used in the analyses.

Evidently, there are various definitions and methodologies to measure free-flow speeds and the aim of this study was therefore to analyse and compare the freeflow speeds measured using different approaches. This study then attempts to develop and evaluate free-flow speed models generated using different measurements of free-flow speeds. Results of this study should provide a better understanding on free-flow speeds with regards to the best-suited measurement approach and subsequently contribute to improve the design and performance assessment of inter urban multilane highways in Malaysia.

\section{STUDY METHODOLOGY}

Field studies were conducted at various four-lane divided and undivided inter urban highways in Malaysia during typical working days; i.e. Tuesday, Wednesday and Thursday using video recording method. Closed-circuit television (CCTV) cameras mounted on a specially fabricated poles were used to record traffic movements at multilane highways during peak hours and off-peak hours. During peak hours, traffic flows were recorded from 7:00 to $8: 00$ am and 5:30 to $6: 30$ pm while for offpeak hours, they were recorded from 10:00 am to 12:00 pm and 2:00 to 4:00 pm. Data from the recorded video were then extracted using an image processing software to obtain the desire traffic parameters such as volume, speed and headway. The speed data were then converted to space-mean speed using the equation developed by Leong and Awang [21] for the Malaysian Highway Capacity Manual [22] as shown in equation (1).

$\bar{v}_{s}=1.021 \bar{v}_{t}-2.528$

where

$\overline{\mathrm{v}}_{\mathrm{t}}=$ Time mean speed

$\overline{\mathrm{v}}_{\mathrm{s}}=$ Space-mean speed

Free-flow speeds were then computed based on three methods of measurements. In Method 1, data set in each direction of travel for each lane was segregated into 5-minute intervals and the linear speed-density relationship graphs were plotted. The free-flow speed is then determined by identifying the speed value when density is zero. In Method 2, free-flow speeds were computed by averaging speeds of all vehicles recorded during low to moderate traffic volume which is less than $1400 \mathrm{pc} / \mathrm{h} / \mathrm{ln}$. Lastly, in Method 3, free-flow speeds were determined based on the average speeds of vehicles with headways more than 8 seconds. Comparative analyses were then conducted to assess the free-flow speeds measured in Methods 1,2 and 3 based on lane position and time variation. Subsequently, multiple linear regression analyses were conducted to develop the free-flow speed estimation models and performance indicators were used to assess and select the best fitted model.

\section{DATA COLLECTION}

Data were collected at 16 sites with 64 lanes of divided and undivided four-lane highways with level gradient in Perlis, Kedah, Perak, Selangor, Pahang and Terengganu, Malaysia. For each segment under study, data were collected at mid segment for both inner and outer lanes. Inner lane is the lane adjacent to the median and is also known as the fast lane while outer lane is the lane adjacent to the shoulder which is the slow lane. All selected sites in this study have the following criteria:

- The segment lengths are limited to $3.5 \mathrm{~km}$.

- Every segment should be at least $1 \mathrm{~km}$ from signalized intersections or major intersections. This is to eliminate the effects of stopping or slow vehicles due to crossing behaviour at signalized intersection or major intersection

- The segment should be flat and straight and should not be affected by major geometric features such as grades, rolling ground or hilly site.

In addition to recording traffic flows, geometric data such as number of lanes, lane width, shoulder width, median clearance and number of access point along the road 
Table 1: Summary of roadway characteristics

\begin{tabular}{|l|c|c|c|c|c|}
\hline Variable & No. of observation & Mean & Min. & Max. & Std. dev. \\
\hline Lane width $(\mathrm{m})$ & 64 & 3.64 & 3.34 & 3.80 & 0.073 \\
\hline Shoulder width $(\mathrm{m})$ & 32 & 2.08 & 0.43 & 4.02 & 0.796 \\
\hline Median clearance $(\mathrm{m})$ & 26 & 0.90 & 0.40 & 2.50 & 0.591 \\
\hline Access point density $(/ \mathrm{km})$ & 32 & 1.67 & 0.29 & 6.86 & 1.265 \\
\hline
\end{tabular}

way were also recorded manually. Measurements of lane widths and shoulder widths were collected at three different locations, i.e. downstream, midpoint and upstream and averaged for further analyses. Table 1 shows the summary of roadway characteristics obtained for all sites.

\section{RESULTS AND DISCUSSIONS}

\section{Comparative Analyses of Free-Flow Speed Based on Measurement Methods}

Analyses on the measured free-flow speed using Methods 1,2 and 3 were conducted. Figure 1 shows the graphical comparisons of free-flow speed values measured in Method 1 with Methods 2 and 3 while Figure 2 shows the comparisons of free-flow speed values measured in Method 2 with Method 3. Comparing the measured free-flow speeds in Method 1 with Methods 2 and 3 , can be seen that generally, the measured free-flow speeds values in Method 1 are higher than the values measured using Methods 2 and 3 while the free-flow speeds measured using Method 2 are almost the same as the values measured in Method 3 . Nevertheless, in Method 2, as the criteria to compute free-flow speed is that the flow rate during data collection must be less than $1,400 \mathrm{pc} / \mathrm{h} / \mathrm{ln}$, the values of flow rate recorded must be checked. Figure 3 shows the range of measured free-flow speeds which is between $59.78 \mathrm{~km} / \mathrm{h}$ to $102.62 \mathrm{~km} / \mathrm{h}$ with recorded flow rates. As can be seen

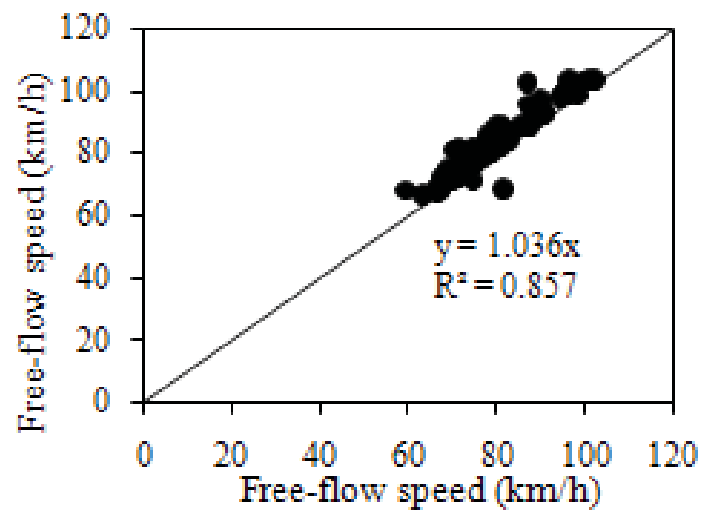

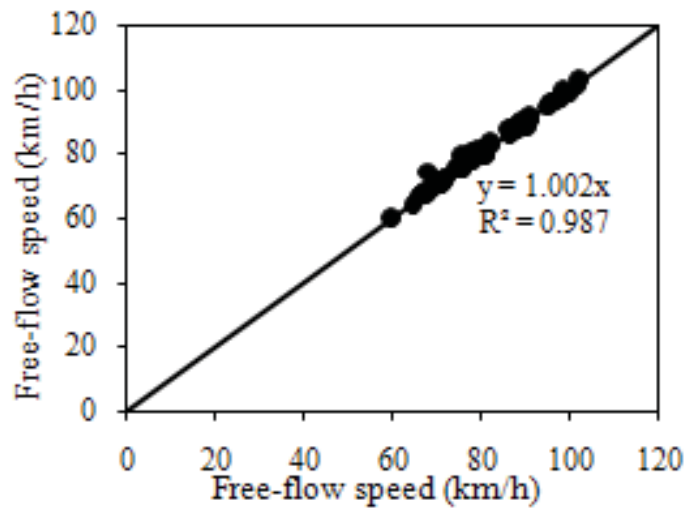

Figure 2: Comparison of measured free-flow speed between Method 2 and Method 3

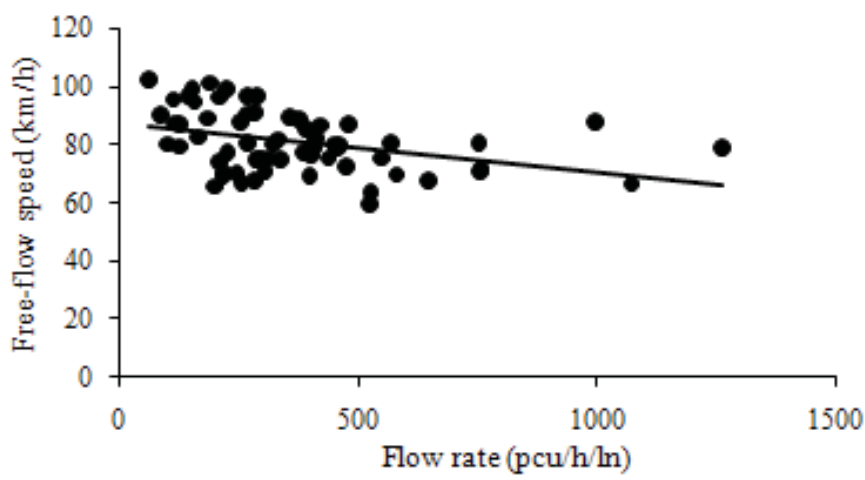

Figure 3: Measured free-flow speed based on Method 2 versus flow rate

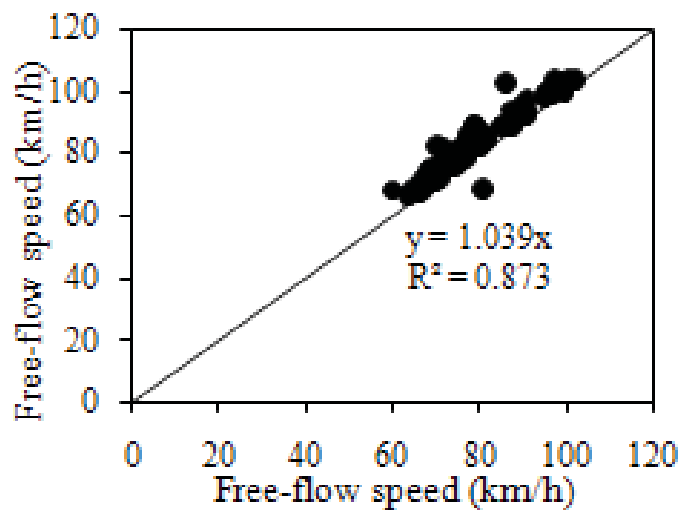

Figure 1: Comparison of measured free-flow speeds (a) Method 1 with Method 2 (b) Method 1 with Method 3 


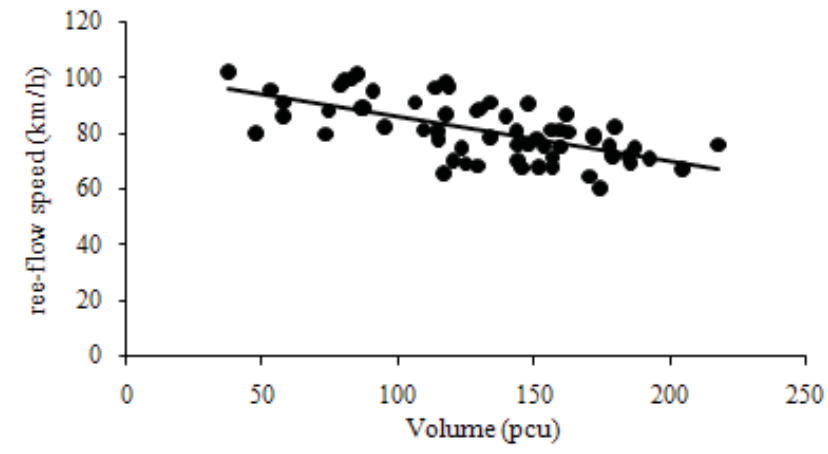

Figure 4: Measured free-flow speed based on Method 3 versus volume (number of vehicles with headways $\geq 8$ seconds)

from the graph, the range of flow rates are between 60 $\mathrm{pcu} / \mathrm{h} / \mathrm{ln}$ to $1264 \mathrm{pcu} / \mathrm{h} / \mathrm{ln}$. Therefore, the flow of vehicles recorded during data collection can be categorized as low to moderate flow condition which is less than 1400 $\mathrm{pc} / \mathrm{h} / \mathrm{ln}$.

Additionally, in Method 3, the free-flow speeds were measured based on the average speeds of vehicles with headways $\geq 8$ seconds. Comparing with the flow rate recorded in Method 2, the volumes of vehicles travelling with headway $\geq 8$ seconds identified in Method 3 are much lower, that is with the minimum of $37 \mathrm{pcu} / \mathrm{h}$ and maximum of only $218 \mathrm{pcu} / \mathrm{h}$. Figure 4 shows the freeflow speeds measured in Method 3 which is between $59.97 \mathrm{~km} / \mathrm{h}$ to $102.17 \mathrm{~km} / \mathrm{h}$ with volume.

\section{Free-flow Speed Models Using Multiple Linear Re- gression}

In this section, three models using three different measurement methods of free-flow speeds were developed using multiple regression. The models as described below, were then assessed using performance indicators to select the best free-flow speed model for inter urban highways in Malaysia.

- Model 1 - based on measured free-flow speed using speed-density graph (Method 1)

- Model 2 - based on average free-flow speed measured during low to moderate traffic flow of less than 1,400 puc/h/ln (Method 2)

- Model 3 - based on average free-flow speeds of vehicles with headways $\geq 8$ s (Method 3 )

In order to develop the regression equation for free-flow speed, ideal conditions must first be determined. Ideal conditions are considered as the most favourable conditions for traffic operation and any deviation from them would affect the performance of the facility. The ideal conditions for multilane highways are as follows:

- Lane width greater than or equal to $3.65 \mathrm{~m}$

- Lateral clearance wider than or equal to $1.8 \mathrm{~m}$

- Divided highways

- No impediment to through traffic due to traffic control or turning vehicles

- Level terrain

Table 2: Summary of regression analysis for free-flow speed models

\begin{tabular}{|c|c|c|c|c|c|}
\hline \multirow{3}{*}{ Model } & \multirow{2}{*}{ Variable } & \multicolumn{2}{|c|}{ Unstandardized coefficients } & \multirow{2}{*}{ t-value } & \multirow{2}{*}{ p-value } \\
\cline { 3 - 5 } & & B & Standard error & & \\
\hline \multirow{3}{*}{1} & LW & 50.950 & 15.263 & 3.338 & 0.001 \\
\cline { 2 - 5 } & SH & 2.458 & 1.208 & 2.035 & 0.046 \\
\cline { 2 - 5 } & APD & 2.905 & 0.558 & 5.202 & $<0.001$ \\
\cline { 2 - 5 } & LD & 20.669 & 1.352 & 15.291 & $<0.001$ \\
\hline \multirow{3}{*}{2} & LW & 46.297 & 14.235 & 3.252 & 0.002 \\
\cline { 2 - 5 } & SH & 4.225 & 1.126 & 3.750 & $<0.001$ \\
\cline { 2 - 5 } & APD & 3.594 & 0.521 & 6.900 & $<0.001$ \\
\cline { 2 - 5 } & LD & 22.085 & 1.261 & 17.518 & $<0.001$ \\
\hline \multirow{3}{*}{3} & LW & 43.502 & 14.218 & 3.060 & 0.003 \\
\cline { 2 - 5 } & SH & 4.462 & 1.125 & 3.966 & $<0.001$ \\
\cline { 2 - 5 } & APD & 3.437 & 0.520 & 6.606 & $<0.001$ \\
\cline { 2 - 5 } & LD & 22.937 & 1.259 & 18.216 & $<0.001$ \\
\hline
\end{tabular}


Model $1\left(R^{2}=0.931\right)$ :

$\mathrm{FFS}=\mathrm{BFFS}-50.950(3.65-\mathrm{LW})-2.458(1.8-\mathrm{LC})-2.905(\mathrm{APD})-20.669(\mathrm{LD})$

Model $2\left(R^{2}=0.952\right)$ :

FFS $=$ BFFS $-46.297(3.65-L W)-4.225(1.8-L C)-3.594($ APD $)-22.085(L D)$

Model $3\left(R^{2}=0.954\right)$ :

$\mathrm{FFS}=\mathrm{BFFS}-43.502(3.65-\mathrm{LW})-4.462(1.8-\mathrm{LC})-3.437$ (APD) -22.937 (LD)

where

BFFS = Base free flow speed

$L W=$ Lane width (ideal lane width $=3.65 \mathrm{~m}$ )

$L C=$ Lateral clearance, adjustment for shoulder width for outer lane and adjustment for median clearance for inner lane (ideal lateral clearance $=1.8 \mathrm{~m}$ )

APD $=$ Access point density

$L D=$ Lane dummy, ( 0 if inner lane, 1 if outer lane $)$

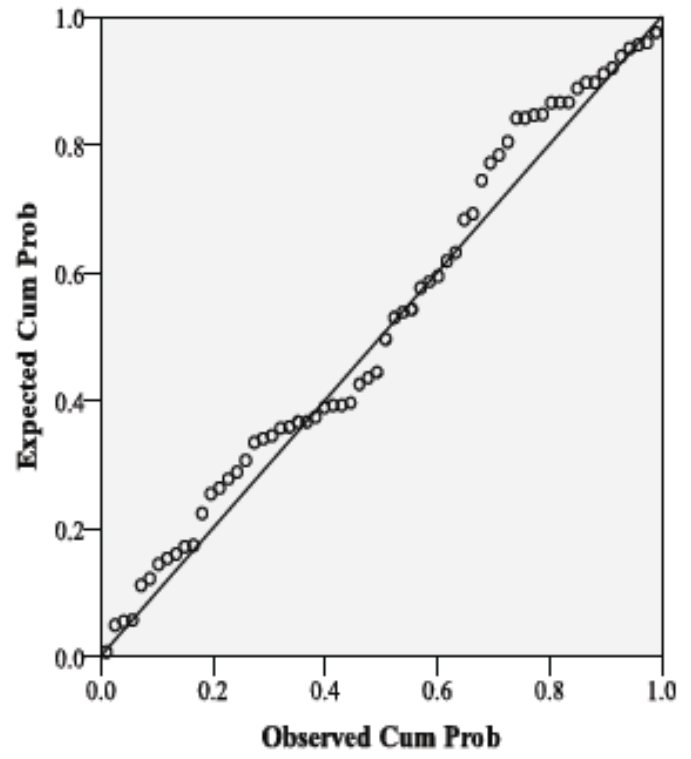

(a)
However, regression analysis requires the assumption of residual (error) to be normally distributed with zero mean and constant variances to obtain the best model. Residual analyses were then conducted to check these assumptions. Normal probability plot, which is an informal graphical tool, can be used to test whether the error terms are normally distributed or otherwise. It is a plot of variable's cumulative proportions (the proportion of the

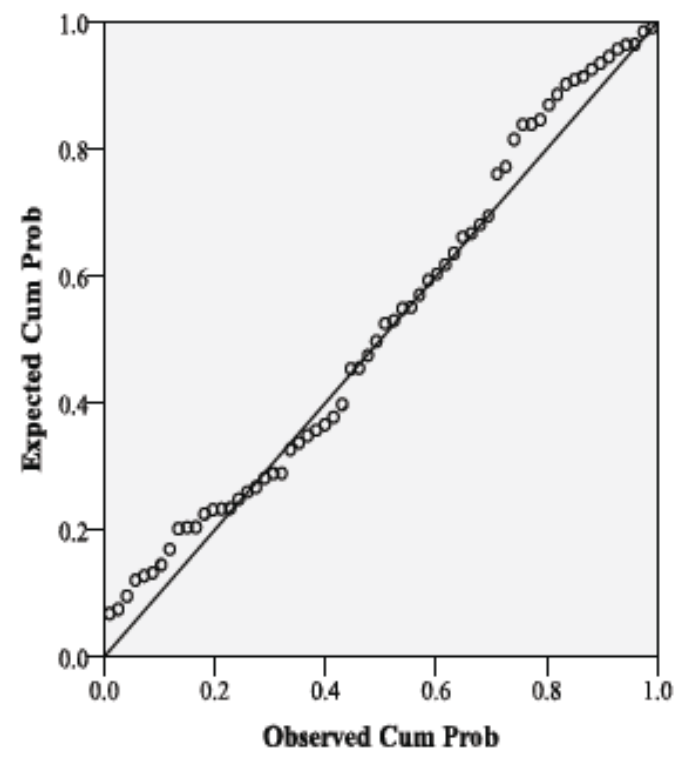

(b)

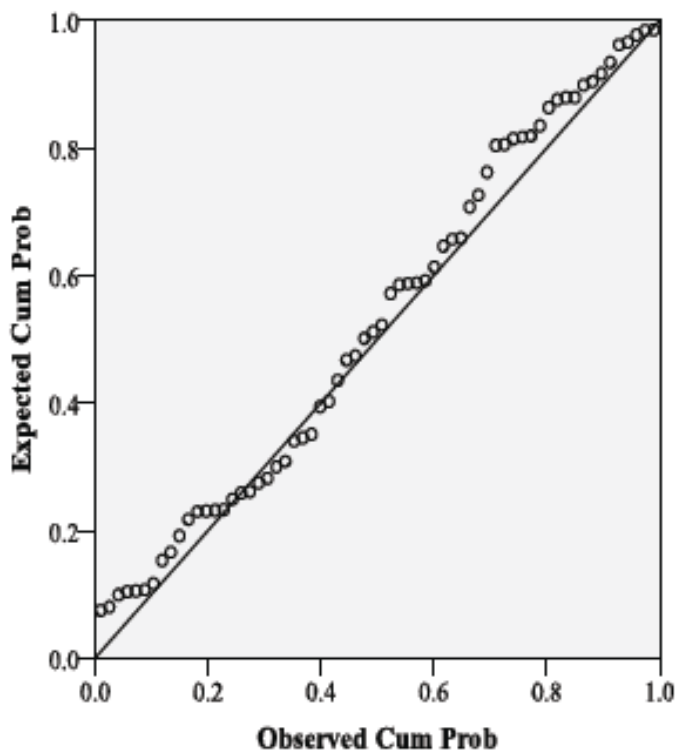

(c)

Figure 5: Normal probability plot generated for free-flow speed models (a) Model 1 (b) Model 2 (c) Model 3 
distribution that is less than the specified value) against the cumulative proportions of a theoretical normal distribution. If the error terms are normally distributed, the points cluster around a $45^{\circ}$ straight line and this indicates the more satisfaction of the assumption. The normal probability plot generated for Models 1, 2 and 3 using a statistical software are as shown in Figure 5 . Based on the results obtained, can be seen that the data points are distributed roughly around the $45^{\circ}$ straight line, hence indicating that the normality assumption for each model is satisfied.

In addition, plotting residuals against fitted values will determine whether non-constant variance existed. As such, the residuals were plotted against the predicted values of the dependent variable and were investigated to determine whether there is any systemic pattern on the plot. If the points in the residual plot show no pattern, then variance is constant. Based on the residual plots shown

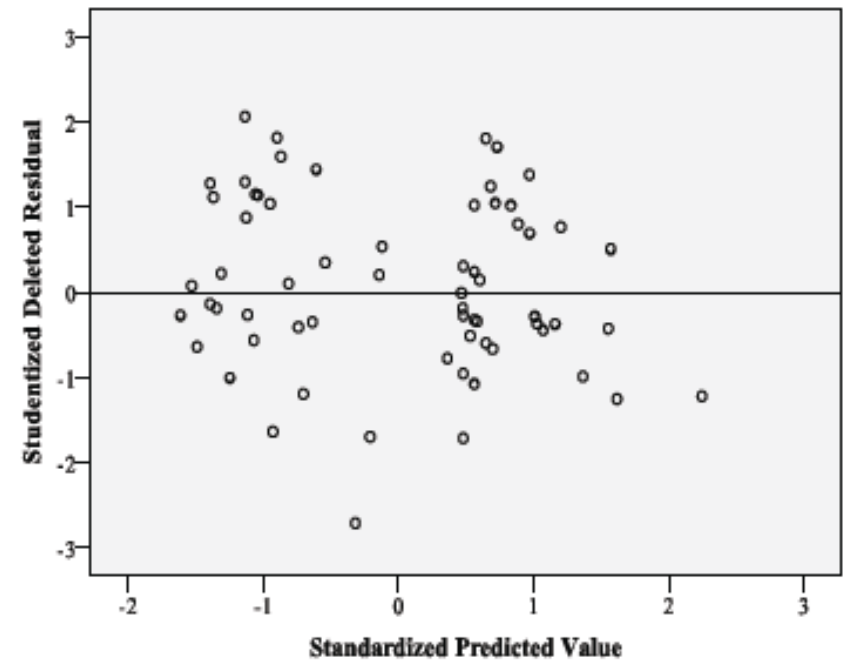

(a) in Figure 6, can be seen that the data points appear to be randomly scattered around the horizontal axis and can be concluded that variance is constant. Therefore, all the regression equations satisfy the assumptions and the models are acceptable.

Subsequently, assessments of the accuracy of the models were conducted using performance indicators $(\mathrm{PI})$. The analyses involved five indicators which consist of two error measures and three accuracy measures. For the error measures, the root mean square error (RMSE) and normalized absolute error (NAE) were calculated while for the accuracy measures, index of agreement (IA), prediction accuracy (PA) and coefficient of determination (R2) were computed. A scoring system was then used to rate the models and the model with the highest score will be regarded as the best model.

In order to produce a good estimator, smaller values of RMSE and NAE which are closer to zero are desired as

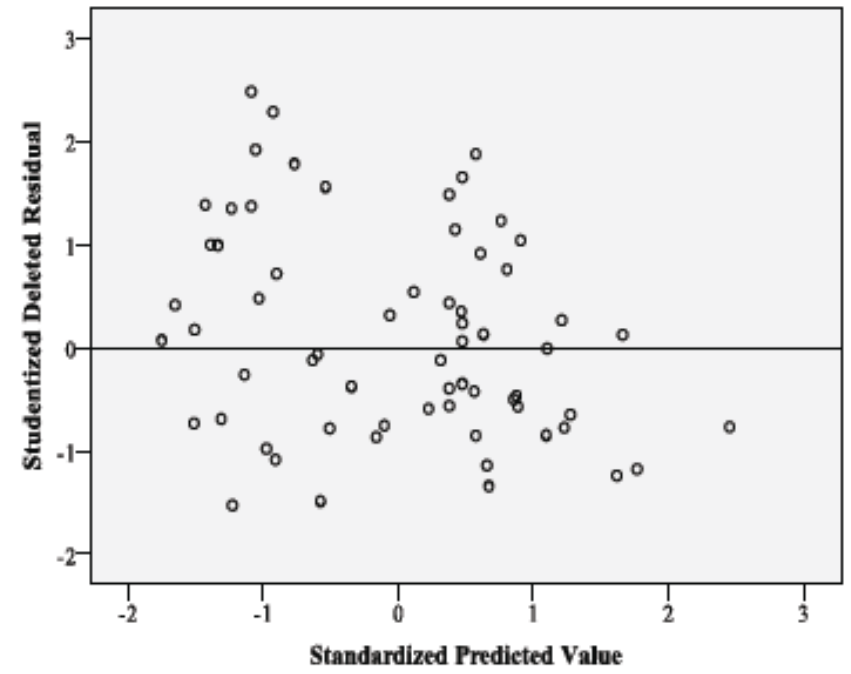

(b)

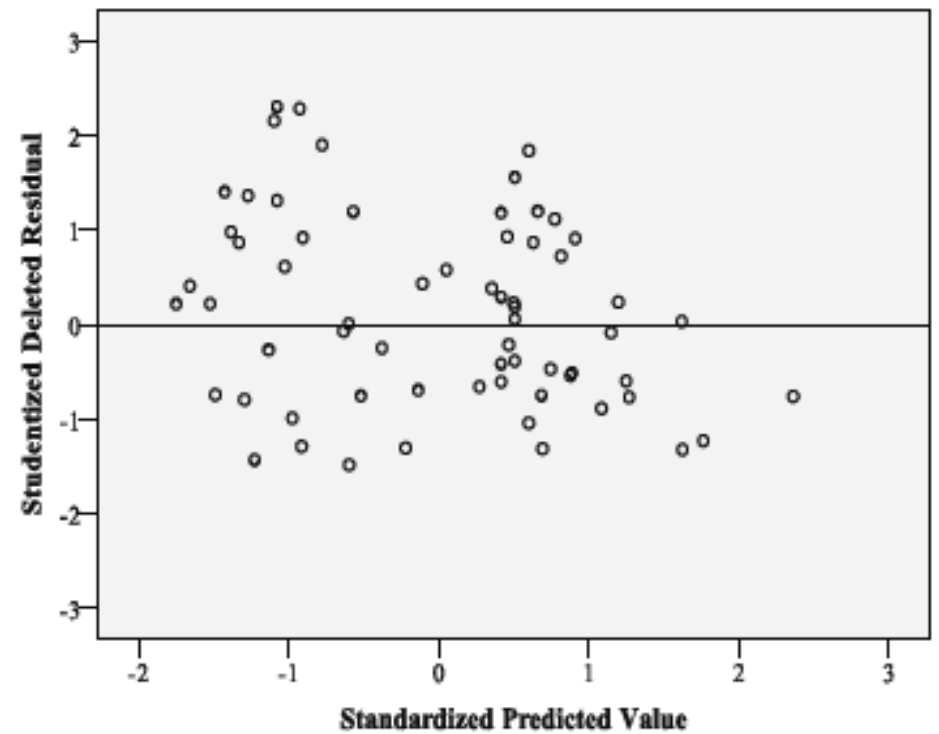

(c)

Figure 6: Residuals against fitted values for free-flow speed models (a) Model 1 (b) Model 2 (c) Model 3 
Table 3: Summary of PI values for free-flow speed models

\begin{tabular}{|c|c|c|c|c|c|c|c|}
\hline \multicolumn{2}{|c|}{ Model } & NAE & RMSE & IA & PA & R2 & Total score \\
\hline \multirow{3}{*}{1} & Value & 0.0604 & 6.5249 & 0.8850 & 0.8181 & 0.931 & \multirow{2}{*}{9} \\
\cline { 2 - 8 } & Score & 3 & 3 & 1 & 1 & 1 & \\
\hline \multirow{3}{*}{2} & Value & 0.0657 & 6.5872 & 0.8856 & 0.8225 & 0.952 & \multirow{2}{*}{9} \\
\cline { 2 - 8 } & Score & 2 & 1 & 2 & 2 & 2 & \multirow{2}{*}{12} \\
\hline \multirow{3}{*}{3} & Value & 0.0659 & 6.5554 & 0.8902 & 0.8307 & 0.954 & \\
\cline { 2 - 8 } & Score & 1 & 2 & 3 & 3 & 3 & \\
\hline
\end{tabular}

they will indicate smaller errors. Hence, score 1 will be given to each indicator that has the highest value while score 3 will be given to each indicator that has the lowest value. As for the measures of accuracy, higher values of PA, IA and R2, with values nearer to 1 are needed for the model to predict well. Therefore, score 1 will be given to each indicator that has the lowest value while score 3 will be given each, to the highest value.

The total score for each model is then calculated by adding the scores obtained in each $\mathrm{PI}$ and can be in the range between 5 to 15 . Total score of 5 is obtained when each of the performance indicator only obtained the minimum score of 1 while total score of 15 is obtained when each of the five indicators obtained maximum score of 3 . The results are summarised in Table 3 . Based on the results shown in Table 11, Models 1 and 2 have the same score of 9 while Model 3 has the highest score of 12 . Therefore, evidently, the choice of the best model will be Model 3 with total score of 12 . The selection of Model 3 as the best model also inferred that the most suitable measurement method of free-flow speed will be based on headways $\geq 8 \mathrm{~s}$.

\section{CONCLUSIONS}

This study compares three different methods of free-flow measurements comprising of free-flow speed based on linear speed-density relationship graphs, the average speed of all vehicles recorded during low to moderate traffic volume and free-flow speeds that were determined based on the average speed of vehicles with headway of more than 8 seconds. Graphical comparison between the free-flow speeds collected from all three methods indicates notable similarity. Subsequent statistical test on the data set utilising one-way ANOVA test, Levene test, post hoc test indicates that the three methods are not significantly different from each other. Further investigation on the effects of lane position and time variation with regards to measured free-flow speed was conducted. Results show that the lane position has a significant impact on the measured mean free-flow speed. Therefore, free-flow speed measured at the inner and outer lanes must be separated for subsequent analyses. However, time variation shows no significant influence on the measured free-flow speeds.

Consequently, three free-flow speed models were developed and tested using multiple linear regression. A dummy variable acting providing an indication of lane position was included in all the regression models to indicate if an inner or outer lane is being measured. Results from regression analyses show that all models fit well with the observed data while the residuals analyses showed that the residuals are normally distributed with mean zero and constant variances. Performance indicator analyses were conducted on the three free-flow speed models generated from the regression analyses. Results concluded that the free-flow speed based on average speed of vehicles with headway of more than 8 seconds is the best model to estimate the free-flow speed of multilane highways in Malaysia. Hence, the results of this study would improve the data collection method of measuring the free-flow speed atinter urban multilane highways. In addition, application of the free-flow speed model developed to estimate free-flow speed for future highways can contribute to improving the design and operational efficiency of multilane highways in Malaysia as the estimation model is developed based on local driving and traffic conditions.

\section{ACKNOWLEDGEMENT}

The authors wish to express their sincere gratitude to Highway Planning Unit, Ministry of Works Malaysia for funding this study and School of Civil Engineering, Universiti Sains Malaysia for the support.

\section{REFERENCES}

1. Transportation Research Board (2010). HCM 2010. Highway Capacity Manual (2010). National Academy of Sciences, United States of America.

2. Ministry of Works Malaysia. (1996). Traffic Study for Malaysia. Kuala Lumpur, Malaysia. 
3. May, A.D. (1990). Traffic Flow Fundamentals. Prentice Hall.

4. Axay, S. S., Chudasama, J. P., Roghelia, A. N., Zala, L. B., Desai, T. A., \&Roghelia, A. N. (2011). Selection of Best Suitable Traffic Model. National Conference on Recent Trends in Engineering \& Technology.

5. Figueroa, A. M., \&Tarko, A. P. (2005). Speed Factors on Two-Lane Rural Highways in Free-Flow Conditions. Transportation Research Board, vol., no.1, 1912, 39 46, https://doi.org/10.1177\%2F0361198105191200105

6. Gong, H., \&Stamatiadis, N. (2008). Operating Speed Prediction Models for Horizontal Curves on Rural FourLane Highways. Transportation Research Board, vol. 2075, no.1, 1 - 7,https://doi.org/10.3141/2075-01

7. Himes, S. C., \& Donnell, E. T. (2010). Speed Prediction Models for Multilane Highways : Simultaneous Equations Approach. Journal of Transportation Engineering ASCE, vol. 136, no. 10, 855 - 862,https://doi. org/10.1061/(ASCE)TE.1943-5436.0000149.

8. Tseng, P., Lin, F., \& Shieh, S. L. (2005). Estimating of Free-Flow Speeds for Multilane Rural and Suburban Highways, Journal of the Eastern Asia Society for Transportation Studies, vol. 6, $1484-1495$.

9. Saifizul, A. A., Yamanaka, H., \& Karem, M. R. (2011). Empirical Analysis of GrossVehicle Weight and Free Flow Speed and Consideration on its Relation with Differential Speed Limit. Accident; analysis and prevention, vol. 43, no. 3, 1068 - 1073, https://doi.org/10.1016/j. aap.2010.12.013

10. Sekhar, C. R., Nataraju, J., Velmurugan, S., Kumar, P. \& Sitaramanjaneyulu, K. (2016). Free Flow Speed Analysis of Two Lane Inter Urban Highways. Transportation Research Procedia 17: 664-673, https://doi. org/10.1016/j.trpro.2016.11.121

11. Bang, K. L., Carlsson, A., \&Palgunadi. (1996). Development of speed-flow relationships for Indonesian rural roads using empirical data and simulation. Transportation Research Record, vol. 1484, 24 - 32.

12. Chiguma, M. L. M. (2007). Analysis of Side Friction Impact on Urban Road Links; Case Study Dar-es-salaam. PhD Dissertation. KTH School of Architecture and the Built Environment. Royal Institute of Technology Stockholm, Sweden.
13. Ghani, A. R., Ibrahim, W. H., \&Sadullah, A. F. (2006). Penentuan Hubungan Laju-Aliran Lalu Lintas Jalan Arteri. Jurnal Kejuruteraan, vol.18, 117-133.

14. Al-Kaisy, A., \& Karjala, S. (2008). Indicators of Performance on Two-Lane Rural Highway: Empirical Investigation. Journal of the Transportation Research Board, vol. 2088, 87-97,http://dx.doi.org/10.3141/2071-11

15. Ali, A. T., Venigalla, M. M., \& Flannery, A. (2007). Prediction Models for Free Flow Speed on Urban Streets. Transportation Research Board 86th Annual Meeting, (No. 07-1954).

16. Silvano, A.P. \& Bang, K.L. (2016). Impact of Speed Limits and Road Characteristics on Free-Flow Speed in Urban Areas. Journal of Transportation Engineering, vol. 142, no. 22, 04015039-1 - 04015039-9,http://dx.doi. org/10.1061/(ASCE)TE.1943-5436.0000800

17. Wu, F., Jiang, J., Hu, W. L., \& Lu, J. (2011). Discerning Free Driving from Car-Following State Based on Trajectory Data from Active Mode Car-Following Experiment. Proceedings of the 11th International Conference of Chinese Transportation Professionals (ICCTP), 776 - 787, http://dx.doi.org/10.1061/41186(421)76

18. Dixon, K. K., Wu, C., Sarasua, W., \& Daniel, J. (1999). Posted and Free -Flow Speeds for Rural Multilane Highways in Georgia. Journal of Transportation Engineering, vol. 125, 487 - 494, https://doi.org/10.1061/(ASCE)0733-947X(1999)125:6(487)

19. Deardoff, M. D., Wiesner, B. N., \& Fazio, J. (2011). Estimating Free-flow Speed from Posted Speed Limit Signs. Procedia Social and Behavioral Sciences, vol. 16, $306-$ 316,https://doi.org/10.1016/j.sbspro.2011.04.452

20. Andrade, G. R., Pitombo C.S., Cunha, A.L. \&Setti, J.R. (2016). A Model for Estimating Free-Flow Speed on Brazilian Expressways. Transportation Research Procedia, vol. 15, 378-388,https://doi.org/10.1016/j.trpro.2016.06.032

21. Leong, L.V. \& Awang, M.A. (2011). Estimating SpaceMean Speed for Rural and Suburban Highways in Malaysia. Journal of Eastern Asia Society for Transportation Studies, vol. 9, 1474-1484.

22. Highway Planning Unit, Ministry of Works Malaysia (2011). Malaysian Highway Capacity Manual 2011. ISBN 978-967-5399-21-3.

Paper submitted: 04.04.2019.

Paper accepted: 21.05.2019.

This is an open access article distributed under the CC BY-NC-ND 4.0 terms and conditions. 